DOI 10.12737/article_5a1d9efe58ee49.25733275

УДК 338.433.4:631.16(470)

ТЕХНИЧЕСКАЯ МОДЕРНИЗАЦИЯ СИСТЕМЫ МЕЛИОРАЦИИ КАК РЕЗЕРВ ПОВЫШЕНИЯ ЭФФЕКТИВНОСТИ СЕЛЬСКОГО ХОЗЯЙСТВА Субаева А.К., Александрова Н.Р., Мавлиева Л.М., Низамутдинов М.М.

Реферат. Одним из малоиспользуемых резервов повышения эффективности сельского хозяйства, посредством технической модернизации является развитие мелиорации. Наиболее эффективным способом механизированного полива является дождевание, что способствует наибольшему попаданию влаги к растениям. Данный способ позволяет увлажнить листовую поверхность, почву и приземный слои воздуха, что спасает в засушливый период. Сокращение парка дождевальной техники в течение ряда лет привело к сокращению площади орошаемых земель, а действующие машины практически не использовались в связи моральным и физическим износом, отсутствием запасных частей для ремонта и высокой энергозатратностью. Показатель применения дождевальных установок в разрезе региона, в частности, товаропроизводителями сельскохозяйственной продукции Республики Татарстан в 2014 году составил 93 процента. При этом 13 районов региона не имеют оросительных машин. Применение дождевальных установок для обработки посевов в сельском хозяйстве экономически оправданно и перспективно. Осуществление модернизации поливальной техники, должно заключаться в замене импортных, дорогостоящих запчастей, деталей более дешевыми и произведенными в России, широкое внедрение открытой оросительной системы с высокой производительностью, низким энергопотреблением. Для реализации данных мероприятий необходимо проведение мер государственной поддержки. При этом утвержденный механизм государственного субсидирования заводов-производителей техники принят с недостатком субсидирования, что приведет к дальнейшему развитию ситуации связанной с техническим обнищанием отрасли сельского хозяйства это предположение доказано прогнозом уровня обеспеченности поливальной техникой по Российской Федерации до 2020 года, который учитывает существующие тенденции развития парка дождевальных и поливальных машин и установок.

Ключевые слова: мелиорация, поливная техника, новые технологии, субсидии, производственная себестоимость, орошаемые земли, оросительная система, дождевальные установки, модернизация, государственная поддержка.

Введение. Одним из малоиспользуемых резервов повышения эффективности сельского хозяйства посредством технической модернизации является развитие мелиорации [1].

Широкое развитие мелиорации в России приходилось на 1966-1990 гг., годы, что привело к упадку данного направления развития сельскохозяйственного машиностроения в связи с отказом от мероприятий по орошению земель[2]. Торможение развития системы мелиорации в сельском хозяйстве связано с отсутствием финансирования строительства новых мелиоративных систем, недостатком средств на реконструкцию и восстановление уже существующих.

Условия, материалы и методы исследований. Парк дождевальных поливных машин и установок, используемых в мелиорации начиная с 2014 года, увеличивается, так в 2015 году процент роста по сравнению с 2010 годом составил $3,7 \%$.

В связи с тем, что до $70 \%$ сельскохозяйственных угодий России расположено в засушливой местности наиболее эффективным способом механизированного полива является дождевание, что способствует наибольшему попаданию влаги к растениям. Данный способ позволяет увлажнить листовую поверхность, почву и приземный слои воздуха, что спасает в засушливый период.
Ю. Ф. Снипич отмечает: «Хорошо зарекомендовали себя такие дождевальные машины, как «Днепр», «Фрегат», «Кубань» и дождевальная установка «Волжанка»[3]. Рассмотрим достоинства и недостатки поливальных установок в таблице 1.

Сокращение парка дождевальной техники в течение ряда лет привело к сокращению площади орошаемых земель, а действующие машины практически не использовались в связи моральным и физическим износом, отсутствием запасных частей для ремонта и высокой энергозатратностью. В данной ситуации наблюдается взаимозависимость между наличием парка данной техники и площадью посеянных сельскохозяйственных культур[4].

Применения дождевальных установок товаропроизводителями сельскохозяйственной продукции Республики Татарстан в 2014 году составил 93 процента. При этом 13 районов региона не имеют оросительных машин. Наибольшей базой гидромелиоративной техники располагают в Мамадышском, Арском, Тукаевском, Сабинском и Кукморском районах. По три дождевальных установки в наличии в Чистопольском и Рыбно-Слободском районах, а в Актанышском, Сармановском и Бавлинском - имеется только по одной машине. 
Э К О О МИ ЧЕСКИЕ НА УКИ

Таблица 1 - Достоинства и недостатки применения дождевальных установок.

\begin{tabular}{|c|c|}
\hline Плюсы & Минусы \\
\hline полная механизация работ & $\begin{array}{l}\text { - высокие затраты металла на изготовле- } \\
\text { ние дожде-вальных машин, труб и } \\
\text { аппаратуры (40-100кг на } 1 \text { га) } \\
\end{array}$ \\
\hline 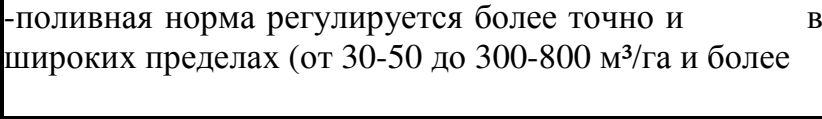 & $\begin{array}{l}\text { - большую энергоемкость процесса дожде- } \\
\text { вания (40-100 кВт/ч на } 1 \text { полив при m=300 } \\
\text { м/га) }\end{array}$ \\
\hline $\begin{array}{l}\text { можно поливать участки с большими уклонами } \\
\text { и со сложным микрорельефом }\end{array}$ & - неравномерность полива при ветре \\
\hline $\begin{array}{l}\text { - забор воды возможен из каналов идущих } \\
\text { в выемке, а также из закрытой сети }\end{array}$ & $\begin{array}{l}\text {-невозможность глубокого промачивания } \\
\text { тяжелых почв при высокой интенсивности } \\
\text { дождя без образования луж и поверхности } \\
\text { стока }\end{array}$ \\
\hline $\begin{array}{l}\text { - исключаются работы по поделке поливных борозд, } \\
\text { улучшаются условия механизации посева, посадки, } \\
\text { обработки и уборки сельскохозяйственных культур }\end{array}$ & $\begin{array}{l}\text { - нецелесообразность } \\
\text { использования на н тяжелых почвах } \\
\text { в условиях сухого и жаркого климата }\end{array}$ \\
\hline $\begin{array}{l}\text { улучшаются микроклимат и развитие корневой } \\
\text { системы, активизируются процессы ассимиляции, } \\
\text { повышаются плодородие почвы и урожайнось } \\
\text { сельскохозяйственных культур }\end{array}$ & \\
\hline \begin{tabular}{|llll} 
можно одновременно & с орошением вносить \\
В почву удобрения & & \\
\end{tabular} & \\
\hline
\end{tabular}

Таблица 2 - Запланированный объем государственной поддержки мелиоративных систем в рамках реализации «Государственной программы развития сельского хозяйства и регулирования рынков сельскохозяйственной продукции, сырья и продовольствия на 2013-2020 годы»

\begin{tabular}{|c|c|c|c|c|c|c|c|c|}
\hline & $\begin{array}{c}2013 \\
\text { год }\end{array}$ & $\begin{array}{c}2014 \\
\text { год }\end{array}$ & $\begin{array}{c}2015 \\
\text { год }\end{array}$ & $\begin{array}{c}2016 \\
\text { год }\end{array}$ & $\begin{array}{c}2017 \\
\text { год }\end{array}$ & $\begin{array}{c}2018 \\
\text { год }\end{array}$ & $\begin{array}{c}2019 \\
\text { год }\end{array}$ & $\begin{array}{c}2020 \\
\text { год }\end{array}$ \\
\hline $\begin{array}{c}\text { Приведение государственных гидротехни- } \\
\text { ческих сооружений в безопасное } \\
\text { в эксплуатации техническое состояние, ед. }\end{array}$ & - & 6 & 20 & 15 & 14 & 19 & 15 & 25 \\
\hline $\begin{array}{c}\text { Объемы и источники финансирования Программы «Развитие мелиоративных земель сельскохо- } \\
\text { зяйственного назначения России на 2014-2020 годы» }\end{array}$ & - & 7,8 & 8,5 & 9,9 & 12,5 & 14,4 & 14,0 & 14,3 \\
\hline $\begin{array}{c}\text { Объем бюджетных ассигнований } \\
\text { неализацию Программы за счет средств } \\
\text { федерального бюджета, млрд.руб. }\end{array}$ & - & & & & & & \\
\hline
\end{tabular}

В Министерстве сельского хозяйства и продовольствия Республики Татарстан отмечают, что из 291 единицы мелиоративных устройств в удовлетворительном техническом состоянии находятся только 272. То есть показатель их использования в 2014 году не превышал 93 процента. Эксперты АПК Татарстана отмечают, что во времена Советского Союза в республике была создана масштабная оросительная система, которая охватывала около 170 тысяч гектаров посевов сельскохозяйственных культур. В 2014 году дождевальные машины смогли оросить поля общей площадью порядка 20 тысяч гектаров. При этом под 15 тысяч гектаров посевов техника была отремонтирована и запущена в работу в течение последних лет.

Осуществление модернизации поливальной техники, должно заключаться в замене импортных, дорогостоящих запчастей, деталей более дешевыми и произведенными в России, широкое внедрение открытой оросительной системы с высокой производительностью, низким энергопотреблением.

Для реализации данных мероприятий необходима проведение мер государственной поддержки. Данные таблицы 2 свидетельствуют о выделении в первые годы более 7 млрд. руб., а в последующие этот показатель должен вырасти в два раза и к 2020 году составить 14,3 млрд руб. Восстановление количества гидротехнических сооружений к 2020 году в отличии от 2014 года должно увеличится в 4 раза.

Количество техники, планируемое субсидировать заводам-производителям при ее реализации по льготным ценам сельскохозяйственным товаропроизводителям, предусматривает лишь 10\%. [5]. В связи с этим утвер- 
ЭКОНОМИЧЕСКИЕ НАУКИ

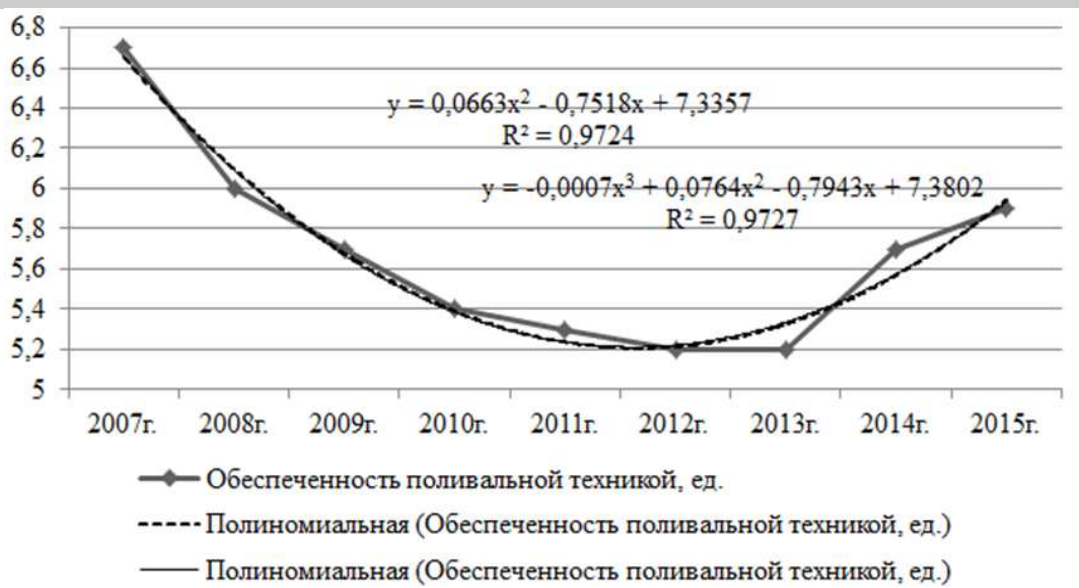

Рисунок 1 - Аналитическое выравнивание ряда динамики обеспеченности поливальной техникой, ед.

Таблица 3 - Прогноз обеспеченности поливальной техникой по РФ до 2020 года

\begin{tabular}{|c|c|c|c|c|c|c|}
\hline Показатели & $2016 г$. & 2017г. & 2018г. & 2019г. & 2020г. & 2025г. \\
\hline Дождевальные и поливные машины и установки, тыс.шт. & 6,3 & 6,9 & 7,6 & 8,4 & 9,3 & 11,0 \\
\hline
\end{tabular}

жденный механизм государственного субсидирования заводов-производителей техники с недостатком субсидирования приведет к дальнейшему развитию ситуации, связанной с техническим обнищанием отрасли сельского хозяйства [6]. Исходя из этого, принятая «Программа развитие мелиоративных земель сельскохозяйственного назначения России на 2014-2020 годы» может быть не выполнена. Поэтому целесообразнее будет спрогнозировать темпы обеспеченности поливальной техники с учетом существующих темпов и тенденций обновления.

Для расчета прогноза обеспеченности поливальной техникой России используем трендовую модель. Использование данных за 2000 -2014 гг. показало существенное снижение обеспеченности сельскохозяйственного производства техникой, что не соответствует фактической тенденции, сложившейся в последние годы. Вследствие этого прогноз обеспеченности поливальной техникой определен на основе данных за 2007-2015 гг. (таблица 3).

На основе фактических и выровненных уровней ряда динамики обеспеченности [7] поливальной техникой по Российской Федерации определены трендовые модели параболического вида. Для определения перспективного развития во внимание был принят коэффициент корреляции трендовой модели (рисунок $1)$.

В таблице 3 представлен прогноз уровня обеспеченности поливальной техникой по Российской Федерации до 2020 года. Данный прогноз учитывает существующие тенденции развития парка дождевальных и поливальных машин и установок.
Согласно аналитическому выравниванию обеспеченность поливальной техникой региона в краткосрочной перспективе увеличится до 7,6 ед., в долгосрочной периоде - до 11,0 ед. Прогноз обеспеченности поливальной техникой определен с учетом аналитического выравнивания ряда динамики показателя по данным 2007-2015 гг. с использованием уравнения параболы 3-го порядка, характеризующимся высоким значением коэффициента детерминации R2=0,9727. В данном случае коэффициент детерминации показывает сильную функциональную зависимость между переменными и характеризует высокую степень реальности данных.

Выводы. Введение новых технологий, внедрение новых форм организации использования поливной техники может стать возможным при правильной организации работы сервисных служб, внедрении новых технологий орошения, открытие при министерстве РФ и министерств регионов отдельного направления в деятельности информационноконсультационных служб по содействию в создании оптовых инженерно-технических рынков для АПК. При всех этих мероприятиях главным фактором внедрения и использования современных систем орошения является государственная поддержка сельскохозяйственных товаропроизводителей в виде субсидий на возмещение затрат за счет средств республиканского бюджета. В том числе и на технику, выпускаемую заводамипроизводителями республики 
Литература.

1. Снипич, Ю.Ф. Совершенствование технических средств орошения дождеванием / Ю.Ф. Снипич. Новочеркасск: ООО «Геликон», 2007. -110 с.

2. Снипич Ю. Ф. Оптимизация нагрузки на поливную технику/ Ю. Ф. Снипич, Л. А. Воеводина, А. Н. Чекунов// Научный журнал КубГАУ [Электронный ресурс. Идентификационный номер информрегистра: 0421100012010]. - Краснодар: КубГАУ, 2011. - №65(01).

3. Снипич Ю. Ф. Выбор и оценка технологий орошения/Ю.Ф. Снипич // Природообустройство.-2011. № 1. -C.16-21.

4.Снипич Ю. Ф. Технологии и агротехнические требования к дождевальным машинам/ Ю. Ф. Снипич // Научный журнал КубГАУ [Электронный ресурс. Идентификационный номер информрегистра: 0421100012117]. - Краснодар: КубГАУ, 2011. - № 68 (04).

5. Водянников, В.Т., Середа, Н.А. Воспроизводство технического потенциала сельского хозяйства в условиях инновационного развития: монография / В.Т. Водянников, Н.А.Середа. - Караваево: Костромская ГСХА, 2014. - $228 \mathrm{c}$.

6. Водянников, В.Т., Рубцов, П.А. Анализ обеспеченности техникой сельскохозяйственных организаций республики Мордовия/ В.Т. Водянников, П.А. Рубцов. // Вестник Федерального государственного образовательного учреждения высшего профессионального образования «Московский государственный агроинженерный университет имени В.П. Горячкина». - 2013. - №3. - С. 79-82.

7. Водянников, В.Т. Методологические и методические основы определения экономической эффективности технических средств/ В.Т. Водянников // Вестник Федерального государственного образовательного учреждения высшего профессионального образования «Московский государственный агроинженерный университет имени В.П. Горячкина». - 2013. - №3. - С. 52-57.

8. Van Duijn J.J. Fluctuations in innovations over time. - Futures, 1981. Vol.13, - № 4. - P. 264-273.

9. Report to the President on ensuring American leadership in advanced manufacturing. - Washington, D.C.: Executive Office of the President. President's Council of Advisors on Science and Technology, 2011.

10. Europe 2020. A strategy for smart, sustainable and inclusive growth. - European Commission, 2002, COM (2010) 2020 final.

Сведения об авторах:

Субаева Асия Камилевна - кандидат экономических наук, доцент, e-mail: subaeva.ak@mail.ru Александрова Наталья Родионовна - кандидат экономических наук, старший преподаватель, e-mail: anr73@mail.ru

ФГБОУ ВО «Ульяновская государственная сельскохозяйственная академия имени П.А. Столыпина», Мавлиева Лейсан Мингалиевна - кандидат экономических наук, доцент, e-mail: leisan-nizami@rambler.ru ФГБОУ ВПО «Казанский государственный аграрный университет», г. Казань, Россия Низамутдинов Марат Мингалиевич - начальник отдела экономического анализа и планирования Министерства сельского хозяйства и продовольствия Республики Татарстан, e-mail: Marat.Nizamutdinov@tatar.ru

\section{TECHNICAL MODERNIZATION OF THE MELIORATION SYSTEM AS A RESERVE FOR IMPROVING THE EFFICIENCY OF AGRICULTURE}

Subaeva A.K., Aleksandrova N.R., Mavlieva L.M.,Nizamutdinov M.M.

Abstract. One of the little-used reserves to improve the efficiency of agriculture, through technical modernization, is the development of melioration. The most effective method of mechanized irrigation is sprinkling, which contributes to the greatest moisture penetration to plants. This method allows you to moisten the leaf surface, soil and ground layers of air, which saves in the dry period. Reducing the park of sprinkling equipment for a number of years led to a reduction in the area of irrigated land, and the operating machines were practically not used due to moral and physical deterioration, the lack of spare parts for repairs and high energy costs. The indicator of the use of sprinklers in the context of the region, in particular, by the agricultural producers of the Republic of Tatarstan in 2014, was 93 percent. At the same time, 13 districts of the region do not have irrigation machines. An application of sprinklers for the cultivation of crops in agriculture is economically justified and promising. The modernization of irrigation equipment should consist in replacing imported, expensive spare parts and parts with cheaper and produced in Russia, wide introduction of an open irrigation system with high efficiency, low energy consumption. To implement these measures, state support measures are necessary. At the same time, the approved mechanism of state subsidizing of machinery manufacturing plants is adopted with a lack of subsidies, which will lead to further development of the situation associated with the technical impoverishment of the agricultural sector. This assumption is proved by the forecast of the level of watering equipment in the Russian Federation until 2020, which takes into account the current trends in the development of a sprinkler park and watering machines and plants.

Key words: melioration, irrigation equipment, new technology, subsidies, production costs, irrigated lands, irrigation system, sprinklers, modernization, state support.

1. Snipich Yu.F. Sovershenstvovanie tekhnicheskikh sredstv orosheniya dozhdevaniem. [Improvement of irrigation technical equipment]. / Yu.F. Snipich. - Novocherkassk: OOO “Gelikon”, 2007. - P. 110.

2. Snipich Yu. F. Optimization of load on irrigation technology. [Optimizatsiya nagruzki na polivnuyu tekhniku]. / Yu. F. Snipich, L. A. Voevodina, A. N. Chekunov // Nauchnyy zhurnal KubGAU. - Scientific journal of KubSAU. [Elektronnyy resurs. Identifikatsionnyy nomer informregistra: 0421100012010]. - Krasnodar: KubGAU, 2011. - №65(01).

3. Snipich Yu. F. Selection and evaluation of irrigation technology. [Vybor i otsenka tekhnologiy orosheniya]. / Yu.F. Snipich // Prirodoobustroystvo. - Nature management. 2011. -№1. - P. 16-21.

4. Snipich Yu. F. Technology and agrotechnical requirements for sprinkling machines. [Tekhnologii i agrotekhniches- 
kie trebovaniya k dozhdevalnym mashinam]. // Nauchnyy zhurnal KubGAU. - Scientific journal of KubSAU. [Elektronnyy resurs. Identifikatsionnyy nomer informregistra: 0421100012117]. - Krasnodar: KubGAU, 2011. - № 68 (04).

5. Vodyannikov V.T., Sereda N.A. Vosproizvodstvo tekhnicheskogo potentsiala selskogo khozyaystva v usloviyakh innovatsionnogo razvitiya: monografiya. [Reproduction of the technical potential of agriculture in the conditions of innovative development: monograph]. / V.T. Vodyannikov, N.A.Sereda. - Karavaevo: Kostromskaya GSKhA, 2014. - P. 228.

6. Vodyannikov V.T., Rubtsov P.A. Analysis of the provision of equipment for agricultural organizations in the Republic of Mordovia. [Analiz obespechennosti tekhnikoy selskokhozyaystvennykh organizatsiy respubliki Mordoviya]. $/$ V.T. Vodyannikov, P.A. Rubtsov. // Vestnik Federalnogo gosudarstvennogo obrazovatelnogo uchrezhdeniya vysshego professionalnogo obrazovaniya "Moskovskiy gosudarstvennyy agroinzhenernyy universitet imeni V.P. Goryachkina". The herald of Federal State Educational Institution of Higher Professional Education "Moscow State Agroengineering University named after V.P. Goryachkin”. - 2013. - №3. - P. 79-82.

7. Vodyannikov, V.T. Methodological and methodological foundations for determining the economic efficiency of technical means. [Metodologicheskie i metodicheskie osnovy opredeleniya ekonomicheskoy effektivnosti tekhnicheskikh sredstv]. / V.T. Vodyannikov // Vestnik Federalnogo gosudarstvennogo obrazovatelnogo uchrezhdeniya vysshego professionalnogo obrazovaniya "Moskovskiy gosudarstvennyy agroinzhenernyy universitet imeni V.P. Goryachkina". - The herald of Federal State Educational Institution of Higher Professional Education "Moscow State Agroengineering University named after V.P. Goryachkin”. - 2013. - №3. - P. 52-57.

8. Van Duijn J.J. Fluctuations in innovations over time. - Futures, 1981. Vol.13, - № 4. - P. 264-273.

9. Report to the President on ensuring American leadership in advanced manufacturing. - Washington, D.C.: Executive Office of the President. President's Council of Advisors on Science and Technology, 2011.

10. Europe 2020. A strategy for smart, sustainable and inclusive growth. - European Commission, 2002, COM(2010) 2020 final.

Authors:

Subaeva Asiya Kamilevna - Ph.D. of Economic Sciences, Associate Professor, e-mail: subaeva.ak@mail.ru Aleksandrova Natalya Rodionovna - Ph.D. of Economic Sciences, Senior Lecturer, e-mail: anr73@mail.ru Ulyanovsk State Agricultural Academy named after P.A. Stolypin, Ulyanovsk, Russia.

Mavlieva Leysan M. - PhD of Economics, Associate Professor, e-mail: leisan-nizami@rambler.ru Kazan State Agrarian University, Kazan, Russia

Nizamutdinov Marat Mingalievich - Head of Economic analysis and planning Department of Ministry of Agriculture and Food of the Republic of Tatarstan, e-mail: Marat.Nizamutdinov@tatar.ru. 